\title{
SUPRESSÃO DA DIGNIDADE HUMANA ATRAVÉS DA ESCRAVIDÃO CONTEMPORÂNEA
}

\section{SUPPRESSION OF HUMAN DIGNITY THROUGH CONTEMPORARY SLAVERY}

\section{CHRISTIANE RABELO BRITTO}

Mestranda em Direito pela Universidade Federal de Sergipe - UFSE.

\section{MARIA HORTÊNCIA CARDOSO LIMA} Mestranda em Direito pela Universidade Federal de Sergipe - UFSE.

\section{RESUMO}

O presente artigo demonstra a existência de pessoas em condições de escravidão moderna, que se submetem às regras do mercado, quando são submetidas às condições laborativas impostas pelo empregador em desrespeito às mínimas garantias constitucionais. Objetiva-se demonstrar que esse fenômeno causa grave desconsideração à dignidade da pessoa humana, ocasionando a inefetividade dos direitos humanos fundamentais, razão pela qual essa temática não pode permanecer silenciada. O desenvolvimento deste trabalho foi construído com o método teóricobibliográfico, inclusive com a pesquisa documental.

PALAVRAS-CHAVE: Direitos Humanos; Inefetividade dos Direitos Humanos; Crise dos Direitos Humanos; Dignidade Humana; Trabalho Escravo Contemporâneo.

\section{ABSTRACT}

This article demonstrates people in conditions of modern slavery, who submit to the 


\section{Personalidade Acadêmica Homenageada:}

Carlos Aurélio Mota de Souza (Universidade Ibirapuera - UNIB)

market's rules, when they are submitted to the labor conditions imposed by the employer in disregard of the minimum constitutional guarantees. The objective is to demonstrate that this phenomenon causes serious disregard for the human person's dignity, causing the ineffectiveness of the fundamental human rights, so that, this theme can not remain silent. The development of this work was built with the theoretical-bibliographic method, including documentary research.

KEYWORDS: Human Rights; Human Rights' Ineffectiveness; Human Rights' Crises; Human Dignity; Contemporary Slavery Labor.

\section{INTRODUÇÃO}

O presente artigo refere-se à crise atual dos direitos humanos, consubstanciados na sua inefetividade, tendo em vista que condutas expressamente vedadas pela Lei Maior continuam sendo toleradas pelo Estado Democrático de Direito, como é o caso da escravidão contemporânea vivenciada por milhares de brasileiros.

A exploração do homem como objeto existe desde os tempos mais remotos da humanidade. No Brasil, desde o seu descobrimento, essa exploração sempre teve como fundamento servir aos interesses daqueles que detêm o poder econômico, trazendo como consequência um sistema de desequilíbrio social.

As injustiças e desigualdades sociais, portanto, refletem-se na própria formação econômica do país, que colocou e ainda coloca o homem dentro de um cenário de evolução social à medida que os ciclos econômicos se desenvolveram. Entretanto, independentemente da posição que o indivíduo ocupa dentro de um determinado contexto socioeconômico, a sua submissão àqueles que detêm o poder econômico somente demonstra a existência de uma situação de escravidão ou, no mínimo, análoga à escravidão nos tempos mais modernos.

Tal situação afasta a efetividade do princípio da dignidade da pessoa humana, como também dos direitos fundamentais sociais, os quais asseguram ao indivíduo os 


\section{Personalidade Acadêmica Homenageada:}

Carlos Aurélio Mota de Souza (Universidade Ibirapuera - UNIB)

elementos mínimos de inserção isonômica no seio social, a exemplo do direito à vida, à integridade física, à liberdade, à livre iniciativa, à saúde, ao exercício de um livre ofício em condições dignas, enfim, direitos esses personalíssimos, portanto, irrenunciáveis, inalienáveis, imprescritíveis.

Por esse motivo, a prática do trabalho escravo é um dos assuntos em evidência na mídia e um dos problemas mais graves que o governo federal tem procurado solucionar através da promoção de políticas públicas para a sua erradicação efetiva. Evidencia-se, portanto, que a escravidão contemporânea corresponde uma forma de exclusão social, uma vez que os escravos modernos são agredidos em todas as esferas de sobrevivência, desde os seus direitos até a sua moral.

A abordagem do presente artigo iniciar-se-á a partir da análise da construção histórica dos direitos humanos, objetivando-se destacar a importância de se compreender todo processo de construção destes direitos a fim de se trabalhar na busca pela sua concretização no cenário atual relacionando-os com o princípio da dignidade da pessoa humana. Seguindo-se com a demonstração da configuração do trabalho escravo contemporâneo. Ademias, far-se-á uma análise da crise atual dos direitos humanos e da vedação aos mesmos a partir do trabalho escravo no Brasil, com o apontamento de sugestões para o enfrentamento desse fenômeno que impacta negativamente a sociedade brasileira.

Para o desenvolvimento deste trabalho, utilizou-se o método dedutivo, a partir da abordagem geral da construção dos direitos humanos e posterior especificação do tema, ao tratar da possibilidade de efetivação destes direitos em tempo de crise. Além deste método, foi utilizado o teórico-bibliográfico, principalmente, com o estudo das obras dos doutrinadores Flávia Piovesan, possibilitando a interação dos estudos sobre a reconstrução dos direitos humanos e a indispensável busca pela sua efetividade, bem como a erradicação da escravidão para o resgate da dignidade humana. 
Personalidade Acadêmica Homenageada:

Carlos Aurélio Mota de Souza (Universidade Ibirapuera - UNIB)

\section{A CONSTRUÇÃO DOS DIREITOS HUMANOS E O PRINCÍPIO DA DIGNIDADE HUMANA COMO FUNDAMENTO BASILAR DA ORDEM CONSTITUCIONAL}

Primeiramente, é importante eliminar possíveis dúvidas a respeito de expressões recorrentes em relação ao tema que são utilizadas como sinônimas, mas que guardam entre si algumas distinções. São elas: direitos humanos, direitos fundamentais e direitos naturais.

Inexiste unanimidade em relação ao consenso na utilização do signo mais adequado para se referir aos direitos humanos e aos direitos fundamentais. A própria Constituição Federal de 1988 faz uso de diversas expressões para mencionar os referidos direitos, tais como: direitos humanos (art. $4^{\circ}, 1 \mathrm{II}$ ); direitos e garantias fundamentais (Título II e art. $5^{\circ}, \S 1^{\circ}$ ), direitos e liberdades constitucionais (art. $5^{\circ}$, LXXI); direitos e garantias individuais (art. 60, §4, IV) (Guerra, 2013).

Para Sarlet (2015), os Direitos Humanos correspondem a direitos inerentes ao indivíduo reconhecidos na esfera internacional, independentemente da sua vinculação com determinada ordem constitucional; por sua vez, os direitos fundamentais são os direitos da pessoa humana reconhecidos e positivados no ordenamento jurídico constitucional interno; finalmente, os direitos naturais do homem assumem uma dimensão pré-estatal (supra estatal), diferentemente do que ocorre com as duas terminologias anteriormente mencionadas.

Passada essa fase, é necessário apresentar a conceituação de direitos humanos, os quais se apresentam como princípios jurídicos, por serem normas abstratas que reclamam a atuação judicial para a efetivação dos conteúdos dessas normas. (RAMOS, 2015, p. 33).

Em relação à conceituação dos Direitos Humanos, André Ramos assevera que:

Os direitos humanos representam valores essenciais, que são explicitamente ou implicitamente retratados na Constituição ou nos tratados internacionais. A fundamentalidade dos direitos humanos pode ser formal, por meio das inscrições desses direitos no rol de direitos protegidos nas Constituições e tratados, ou pode ser material, sendo considerado parte integrante dos direitos humanos aquele que - mesmo não expresso - é indispensável para 


\title{
Personalidade Acadêmica Homenageada:
}

\section{Carlos Aurélio Mota de Souza (Universidade Ibirapuera - UNIB)}

a promoção da dignidade humana. (RAMOS, 2016, pág. 30).

Os direitos humanos correspondem a um aglomerado de normas jurídicas fundamentais imprescindíveis para assegurar a vida digna dos seres humanos, proporcionando-Ihes condições adequadas de existência, a fim de que esses indivíduos possam participar ativamente da vida da sua comunidade (RAMOS, 2015).

Neste sentido, é considerado um conjunto de valores históricos, básicos e fundamentais, intrínsecos à vida digna do indivíduo, abrangendo as dimensões jurídica, política, psíquica, econômica e física do indivíduo, representando uma condição fundante da vida do ser humano. (MORAIS, 2011).

São direitos inerentes à humanidade do indivíduo pelo simples fato de ser pessoa. Tais direitos estão ligados a um mínimo indispensável para atender tanto às necessidades básicas materiais de subsistência como ligadas ao bem-estar psíquico do indivíduo.

Alexandre Pagliarini (2012) afirma que o Direito Constitucional define Direitos Humanos como sendo normas cogentes provenientes do Direto Constitucional de um dado Estado, independentemente de serem normas-regras ou normas-princípios de Direitos Humanos oriundas do Direito Internacional Público. Na visão do autor, as expressões Direitos Humanos e Direitos Fundamentais são sinônimas.

Nesse diapasão, Pagliarini assevera que:

\begin{abstract}
Direitos Humanos são normas jurídicas contidas em regras, princípios e costumes, escritos ou não - mas que tenham sido positivados pelo Estado ou pela Comunidade Política Internacional - que salvaguardam o indivíduo e a coletividade em face da atuação do próprio Estado, da própria Comunidade Jurídica Internacional organizada e até dos particulares (PAGLIARINI, p. 2012).
\end{abstract}

Assim sendo, conclui-se que os Direitos Humanos correspondem não só aos preceitos fundamentais contidos na Constituição, mas também aos direitos supra nacionais exarados pelas Cortes Constitucionais Internacionais e que visam proteger aqueles bens indisponíveis e essenciais à vida humana.

Os direitos e garantias positivados no texto constitucional de 1988 são regras 


\section{Personalidade Acadêmica Homenageada:}

Carlos Aurélio Mota de Souza (Universidade Ibirapuera - UNIB)

que atestam a proteção aos Direitos do Homem e do Cidadão, aos Direitos Humanos, defendendo a liberdade em todos os seus aspectos. Tal assertiva é reforçada pelo fato de que esses direitos positivados constitucionalmente se aplicam no âmbito interno e externo na medida em que tratados e convenções internacionais são incorporadas ao ordenamento jurídico, que ao disporem sobre Direitos Humanos passam a dispor da proteção constitucional própria, com quórum privilegiado de aprovação.

$\mathrm{Na}$ garantia dos direitos fundamentais, pode-se afirmar que além dos dispositivos arrolados no art. $5^{\circ}$ da Carta Constitucional possuírem status de fundamental, em razão da distribuição temática feita pelo constituinte, outras garantias fundamentais são encontradas ao longo do Texto Constitucional. Nesse diapasão temse a dignidade da pessoa humana como princípio fundamental maior e norteador da proteção jurídico constitucional do cidadão, insculpido no art. $1^{\circ}$, III, como fundamento da República Federativa do Brasil. Por conseguinte, o respeito a este princípio representa a garantia estatal do desenvolvimento da personalidade do indivíduo.

O tema sobre direitos humanos logrou destaque gradativamente, possuindo como objetivo principal a proteção e efetividade do Princípio da Dignidade da Pessoa Humana. Por esta razão, é imprescindível fazer uma digressão à evolução histórica da reconstrução de tais direitos.

Os direitos humanos emergem de processos que demandam lutas emancipatórias em prol da firmação da dignidade humana. Nesse horizonte de lutas destaca-se especialmente a Declaração Universal dos Direitos Humanos (DUDH) de 1948, constituindo um marco do contexto histórico, ao qual ela faz parte. Esse documento emerge ao mundo jurídico como resposta aos arbítrios totalitários. (PIOVESAN, 2015a).

O processo de criação normativa dos direitos humanos ocorre no pósSegunda Guerra Mundial, como uma resposta jurídica às atrocidades e horrores perpetrados em face dos judeus durante o nazismo. É a partir da DUDH que se desenvolve a concepção contemporânea de direitos humanos, através da internacionalização desses direitos, objetivando evitar que os horrores cometidos durante o nazismo não fossem repetidos. (PIOVESAN, 2015a).

Nesse contexto, Flávia Piovesan assim se posiciona: 


\section{Personalidade Acadêmica Homenageada: \\ Carlos Aurélio Mota de Souza (Universidade Ibirapuera - UNIB)}

[...] se vislumbra o esforço de reconstrução dos direitos humanos, como paradigma e referencial ético a orientar a ordem internacional contemporânea. Com efeito, no momento em que os seres humanos se tornam supérfluos e descartáveis, no momento em que vige a lógica da destruição, em que é cruelmente abolido o valor da pessoa humana, torna-se necessária a reconstrução dos direitos humanos, como paradigma ético capaz de restaurar a lógica do razoável. A barbárie do totalitarismo significou a ruptura do paradigma dos direitos humanos, por meio da negação do valor da pessoa humana como valor-fonte do Direito. Se a Segunda Guerra significou a ruptura com os direitos humanos, o Pós-Guerra deveria significar a sua reconstrução (PIOVESAN, 2015a, p. 45).

Impende mencionar que nos campos de extermínio nazistas, os judeus eram assassinados de acordo com a explicação oferecida pelas doutrinas à razão do ódio: independentemente de vícios ou virtudes pessoais. Seguindo ordens, os assassinos, orgulhosos de sua eficiência, contribuíram para um ciclo inumano e impessoal de eventos, retratando a doutrina do antissemitismo. (ARENDT, 2015).

Diante desses fatos, pairou no mundo o sentimento da imprescindibilidade da criação de dispositivos internacionais capaz de garantir direitos do indivíduo contra o estado e que fossem marcados pela universalidade. Nesse sentido, Flávia Piovesan discorre:

\footnotetext{
O Processo de universalização dos direitos humanos permitiu a formação de um sistema internacional de proteção desses direitos. Tal sistema é integrado por tratados internacionais de proteção que refletem, sobretudo, a consciência ética contemporânea compartilhada pelos Estados, na medida em que invocam o consenso internacional acerca de temas centrais aos direitos humanos, na busca da salvaguarda de parâmetros protetivos mínimos - do "mínimo ético irredutível." (PIOVESAN, 2015a, p. 49).
}

Essa concepção é caracterizada por três conquistas resultantes de processos emancipatórios em que os direitos humanos são universais, pertencentes a todas as pessoas indistintamente; seu fundamento ético é a dignidade da pessoa humana e esses direitos são interdependentes, inter-relacionados e indivisíveis. (PIOVESAN, 2015b).

É importante destacar que a DUDH nasceu como uma carta de intenções, mas no decorrer do tempo passou a ser adotada pelos Estados, passando a figurar no direito costumeiro, através da presença de seu conteúdo em inúmeros documentos, inclusive nas jurisprudências dos Estados e Tribunais Internacionais. 


\title{
Personalidade Acadêmica Homenageada:
}

Carlos Aurélio Mota de Souza (Universidade Ibirapuera - UNIB)

Desta maneira, representa o primeiro documento legal que reconheceu direitos próprios dos seres humanos que não poderiam ser violados pelo Estado. Trata-se da primeira tentativa de limitação do comportamento do Estado em relação aos direitos dos cidadãos. (ÁVILA, 2014).

Um sistema normativo internacional de proteção dos direitos humanos começa a ser formulado, constituindo um novo paradigma centrado nas relações Estado/povo, na emergência de um Direito Internacional dos Direitos Humanos e na tendencial elevação da dignidade da pessoa humana a pressuposto de todos os constitucionalismos (PIOVESAN, 2015b).

Em relação ao positivismo universal dos direitos humanos, Piovesan atesta que:

\begin{abstract}
Em face da crescente consolidação deste positivismo universal concernente aos direitos humanos, pode-se afirmar que os tratados internacionais de proteção aos direitos humanos refletem, sobretudo, a consciência ética contemporânea compartilhada pelos Estados, na medida em que invocam o consenso internacional acerca de parâmetros protetivos mínimos referentes à dignidade humana, isto é, o mínimo ético irredutível que deve ser respeitado pelos Estados. [...]. (PIOVESAN, 2015b).
\end{abstract}

A universalização dos direitos humanos foi a responsável pelo resgate do princípio da dignidade da pessoa humana, momento em que tal princípio passa a compor o núcleo dos direitos humanos, considerado como valor fundamental, o qual deve ser sempre respeitado e protegido.

A dignidade da pessoa humana impõe o dever de evitar qualquer sofrimento humano, devendo sempre estar embasado no respeito à alteridade, sendo que as diferenças sociais deverão ser enfrentadas como elementos de afirmação e proteção desses direitos.

Tal princípio constitui o núcleo central, como também a origem dos direitos fundamentais e humanos, representando a tutela da liberdade, da igualdade, sendo imprescindível para a exigibilidade e efetivação dos direitos.

A dignidade da pessoa humana será sempre suprimida quando a pessoa for rebaixada a objeto, mero instrumento, enfim, tratada como coisa. Desta forma, a dignidade da pessoa humana engloba necessariamente o respeito e a proteção à 


\section{Personalidade Acadêmica Homenageada:}

\section{Carlos Aurélio Mota de Souza (Universidade Ibirapuera - UNIB)}

integridade física e psíquica do indivíduo. A concepção de homem-objeto representa a antítese da noção de dignidade humana. (SARLET, 2015). Logo, resta evidente que as condutas perpetradas para a configuração do trabalho escravo moderno atingem frontalmente os direitos humanos, especialmente a dignidade das vítimas desse fenômeno.

Essa situação afasta a efetividade da dignidade da pessoa humana, a qual assegura ao ser humano elementos mínimos de inserção isonômica no seio social, garantindo-o direitos fundamentais indissociáveis do seu status natural, a exemplo do direito à vida, à integridade física, à liberdade, à livre iniciativa, à saúde, ao exercício de um livre ofício em condições dignas, enfim, direitos esses personalíssimos, logo, irrenunciáveis, inalienáveis, imprescritíveis.

A Declaração de 1948 dispõe no art. 25 que cada pessoa faz jus a um padrão de vida que garanta a sua saúde e bem-estar, juntamente com a da sua família. Ao estabelecer estes padrões mínimos de sobrevivência, está implicitamente estipulado os parâmetros necessários para que seja respeitado o princípio da dignidade humana.

Vislumbra-se, desta forma, que para a efetivação do dispositivo supra é imprescindível a promoção da garantia de alguns direitos básicos dos trabalhadores, a fim de que Ihes sejam garantidas condições dignas de trabalho. Para tanto, as atividades laborativas devem ser executadas em ambiente saudável, apto a resguardar a personalidade e bem-estar do trabalhador.

Neste diapasão, tem-se o Estado como o responsável por adotar as medidas necessárias para a promoção da dignidade humana mediante a efetivação do valor social do trabalho, que constitui elemento fundante da ordem econômica e social, devendo ser sempre preservada a humanidade da pessoa do trabalhador.

\section{A ESCRAVIDÃO CONTEMPORÂNEA E SUA CONFIGURAÇÃO JURÍDICA}

Não há como precisar, na história, um momento exato para o surgimento da escravidão. Como forma de trabalho humano, vê-se que a escravidão já significou um avanço na história da humanidade, uma vez que em tempos mais longínquos, o 


\section{Personalidade Acadêmica Homenageada:}

Carlos Aurélio Mota de Souza (Universidade Ibirapuera - UNIB)

homem mais forte conquistava o território do mais fraco e se apoderava de seus bens. (TREVISAM, 2015, p. 48). O que se percebe, ao longo da evolução sociocultural, é que há variações no processo de escravidão relacionadas a fatores econômicos, políticos, sociais, culturais e religiosos.

É cediço que o Brasil foi o último país a abolir a escravidão, o que ocorreu de forma gradativa devido a questões econômicas, época em que o país dispunha apenas da mão-de-obra escrava para realizar a maioria das atividades laborativas, especialmente a agricultura. A Lei Áurea decretou o fim da escravidão em 13 de maio de 1888, entretanto o trabalho em condições análogas à de escravo persiste até a atualidade.

A escravidão moderna adquiriu nova roupagem ao não estar diretamente ligada à imagem de pessoas acorrentadas em senzalas, apresentando como traço identificador, principalmente, o cerceamento do direito de ir e vir, o qual pode assumir tanto a forma física como a psicológica.

É importante evidenciar que a proibição da escravidão ganhou força através da luta contra o tráfico negreiro, no final do séc. XVIII, através de normatizações internacionais, tendo-se como primeiro documento legal o Tratado de Paris de 1814, elaborado com o fito de impedir o tráfico negreiro nas colônias pertencentes à Inglaterra e à França.

A Convenção sobre a Escravatura/1926, emendada pelo Protocolo Suplementar em 1953, é considerada o primeiro instrumento de proteção a favor da erradicação do trabalho escravo. Em 1956, surge a Convenção Suplementar sobre a Abolição da Escravatura, a qual objetiva abolir a escravidão, o tráfego de escravos e as práticas análogas à escravidão. Tais instrumentos foram promulgados pelo Decreto n. $58.563 / 1966$.

Importante destacar a preocupação da normatização internacional, em comento, em tutelar a liberdade como um direito pertencente a todo o ser humano. Encontra-se em consonância com a Declaração Universal dos Direitos do Homem, no sentido de reconhecer a impossibilidade de submissão de qualquer pessoa à escravidão ou servidão, bem como a proibição da escravidão e o tráfico de escravos em todas as suas formas. A Convenção n. 29/1930 da Organização Internacional do 


\section{Personalidade Acadêmica Homenageada:}

Carlos Aurélio Mota de Souza (Universidade Ibirapuera - UNIB)

Trabalho (OIT), denominada Convenção sobre Trabalho Forçado, trata da erradicação do trabalho forçado ou obrigatório, em todas as suas formas e foi promulgada pelo Decreto n. 41.721/1957. Apresenta a definição de trabalho forçado ao mencionar ser o trabalho exigido de uma pessoa sob ameaça de punição ou aquele com a ausência de voluntariedade ${ }^{1}$.

Em 2014 a Convenção n. 29/30 passa por um processo de atualização através da elaboração do Protocolo de 2014, dispondo sobre o tráfico humano como forma moderna de escravidão, como também, da Recomendação n. 203/2014, com orientações técnicas a respeito da sua implementação. Importante mencionar que esses instrumentos não foram ratificados pelo Brasil.

O Protocolo de 2014 estabelece a obrigatoriedade dos Estados-membros de adotar medidas efetivas para a prevenção e a supressão desse fenômeno, além de promover à proteção das vítimas por meio do acesso às ações legais adequadas, para a compensação da violação de seus direitos humanos e responsabilização dos autores de tais práticas.

Importante evidenciar o conteúdo das medidas a serem adotadas para a prevenção do trabalho escravo presentes no Protocolo de 2014, como a educação, com o objetivo de suprir a vulnerabilidade das vítimas; a educação dos próprios empregadores, com o fito de evitar futuro envolvimento nessa prática por desconhecimento do fenômeno; o incremento dos serviços de inspeção no trabalho; a proteção dos trabalhadores migrantes, especialmente no sentido de evitar práticas abusivas e enganosas no momento do recrutamento e ações com a finalidade de apontar as causas e fatores que geram a situação de escravização para facilitar o seu enfrentamento.

A Convenção n. 105/1957, promulgada pelo Decreto n. 58.822/1966, intitulada Convenção sobre a Abolição do Trabalho Forçado, foi elaborada com vistas a tutelar outras proposições referentes a abolição de formas de trabalhos forçado ou obrigatório violadoras dos direitos humanos, ao coibir o trabalho forçado ou obrigatório

\footnotetext{
${ }^{1}$ Art. $2^{\circ}$, § 1. Em consequência da presente Convenção, a expressão "trabalho forçado ou obrigatório" designa todo trabalho ou serviço exigido de um indivíduo, sob ameaça de uma pena qualquer e para o qual esse indivíduo não se oferece voluntariamente.
} 


\section{Personalidade Acadêmica Homenageada: \\ Carlos Aurélio Mota de Souza (Universidade Ibirapuera - UNIB)}

como forma de coerção ou de educação política; como forma de disciplina no trabalho; como castigo devido à participação em greve e como discriminação².

A Declaração Universal de Direitos Humanos/1948 - DUDH estabelece a proibição do trabalho escravo nos artigos IV e $\mathrm{V}$, no sentido de ser inadmissível a escravidão, a servidão, como também o tráfico de escravos, a tortura e o tratamento cruel, desumano e degradante ${ }^{3}$. Não apresenta uma definição para o trabalho escravo, apenas refere-se à proibição da escravidão e tráfico de pessoas.

A Convenção Americana sobre Direitos Humanos (Pacto de San José da Costa Rica de 1969), promulgado pelo Decreto n. 678/1992, protege a integridade física em seu art. $5^{\circ}$ e proíbe a escravidão e a servidão no art. $6^{\circ}$. Apesar de não apresentar uma definição expressa do trabalho escravo, a mesma pode ser extraída do art.6-, incisos 1 e 2, como sendo o trabalho executado que afete a dignidade, bem como a capacidade física e intelectual do trabalhador. ${ }^{4}$

Importante destacar que com a edição da Declaração Universal de Direitos Humanos/48, incorporou-se ao cerceamento da liberdade, a proteção da dignidade humana, que pode ser depreendido do preâmbulo ao reconhecer a dignidade como um valor inerente a todo ser humano e a proteção dos direitos humanos em detrimento ao império das leis 5 .

\footnotetext{
2 Art. 1 Todo País-membro da Organização Internacional do Trabalho que ratificar esta Convenção, compromete-se a abolir toda forma de trabalho forçado ou obrigatório e dele não fazer uso: a) como medida de coerção, ou de educação política ou como sanção dirigida a pessoas que tenham ou exprimam certas opiniões políticas, ou manifestem sua oposição ideológica à ordem política, social ou econômica estabelecida; b) como método de mobilização e de utilização da mão-de-obra para fins de desenvolvimento econômico; c) como medida de disciplinar mão de obra; d) como punição por participação em greves; e) como medida de discriminação racial, social, nacional ou religiosa.

${ }^{3}$ Artigo IV Ninguém será mantido em escravidão ou servidão; a escravidão e o tráfico de escravos serão proibidos em todas as suas formas; Artigo V Ninguém será mantido em escravidão ou servidão; a escravidão e o tráfico de escravos serão proibidos em todas as suas formas.

${ }^{4}$ Art. 6.1. Ninguém pode ser submetido a escravidão ou a servidão, e tanto estas como o tráfico de escravos e o tráfico de mulheres são proibidos em todas as suas formas. 2. Ninguém deve ser constrangido a executar trabalho forçado ou obrigatório. Nos países em que se prescreve, para certos delitos, pena privativa da liberdade acompanhada de trabalhos forçados, esta disposição não pode ser interpretada no sentido de que proíbe o cumprimento da dita pena, imposta por juiz ou tribunal competente. O trabalho forçado não deve afetar a dignidade nem a capacidade física e intelectual do recluso.

${ }^{5}$ Preâmbulo. Considerando que o reconhecimento da dignidade inerente a todos os membros da família humana e de seus direitos iguais e inalienáveis é o fundamento da liberdade, da justiça e da paz no mundo, Considerando que o desprezo e o desrespeito pelos direitos humanos resultaram em atos bárbaros que ultrajaram a consciência da Humanidade e que o advento de um mundo em que os todos gozem de liberdade de palavra, de crença e da liberdade de viverem a salvo do temor e da necessidade
} 


\title{
Personalidade Acadêmica Homenageada:
}

Carlos Aurélio Mota de Souza (Universidade Ibirapuera - UNIB)

Nesse diapasão, a Convenção Americana sobre Direitos Humanos, ratificada pelo Decreto n. 678/1992, estabelece que o trabalho forçado ou obrigatório não pode violar a dignidade do indivíduo6.

A variedade de termos utilizados para referenciar a prática escravocrata convergem para o fato de que essa conduta aniquila a dignidade humana e transmuta a pessoa em objeto. Esse fato é reforçado com o posicionamento de Rina Gómes (2001), ao afirmar que:

\begin{abstract}
Así la esclavitud no es una categoría fija para todo tiempo y lugar, assume formas y representaciones muy distintas de un lugar a otro, con una especificidad histórica, temporal y espacial, donde los individuos son trabajadores forzados en una sociedad concreta y traduce, o pone en evidencia, una forma de dominación, de control y uso de poder. La esclavitud es una forma de explotacíon que la distingue de otras formas por la dualidad de los sujetos sociales: son personas y son mercancias, y como personas son propriedad. (GÓMEZ, 2001, p.33).
\end{abstract}

Nesse contexto, é importante trazer à baila, também, as lições de Vanessa Rodríguez (2013):

\begin{abstract}
Resulta necesario recordar que es el status o condición de una persona sobre la cual se ejerce todo o alguno de los poderes associados al derecho de propriedade; $y$ la servidumbre es la sujecíon de una persona bajo la autoridad de otra con subordinación a la voluntad y los designios de otra sin que tenga opción a decidir, protestar o discrepar, con la total perdida de la libertad y con la consecuente despersonalización y captación de voluntad. (RODRÍGUEZ, 2013, p. 82).
\end{abstract}

Desta forma, resta evidente que a comunidade internacional ecoa no sentido de reconhecer o princípio da proibição das atividades que reduzam as pessoas à condição análoga à de escravo. O Trabalho escravo contemporâneo é tratado como uma afronta aos direitos humanos, uma vez que tolhe a liberdade do ser humano,

foi proclamado como a mais alta aspiração do ser humano comum, Considerando ser essencial que os direitos humanos sejam protegidos pelo império da lei, para que o ser humano não seja compelido, como último recurso, à rebelião contra a tirania e a opressão.

${ }^{6}$ Art. 6.2 Ninguém deve ser constrangido a executar trabalho forçado ou obrigatório. Nos países em que se prescreve, para certos delitos, pena privativa da liberdade acompanhada de trabalhos forçados, esta disposição não pode ser interpretada no sentido de que proíbe o cumprimento da dita pena, imposta por juiz ou tribunal competente. O trabalho forçado não deve afetar a dignidade nem a capacidade física e intelectual do recluso. 


\section{Personalidade Acadêmica Homenageada:}

Carlos Aurélio Mota de Souza (Universidade Ibirapuera - UNIB)

aniquila a sua honra, promove a sua exploração e muitas vezes leva essas pessoas à morte, sendo considerado um crime contra a humanidade.

No Brasil, tem-se a Constituição Federal em seu art. 5ำ, incisos III assevera "III - ninguém será submetido a tortura nem a tratamento desumano ou degradante". O inciso XLVII afirma a proibição de penas de trabalhos forçados.

$\mathrm{O}$ art. 243 do mesmo diploma foi alterado recentemente pela Emenda Constitucional $n^{\circ} 81$, de 2004, passando a prever a expropriação de propriedades rurais e urbanas onde forem encontradas práticas escravocratas, assim como a apreensão de todo e qualquer bem de valor econômico encontrados nessas terras.

O art. 149 do Código Penal, aletrado em 2003, tipifica o crime de redução da pessoa à condição análoga à de escravo, trazendo em seu bojo as formas análogas de trabalho comparada à escravidão. Trabalhos forçados, servidão por dívida, jornada exaustiva de trabalho, condições degradantes de trabalho e cerceamento de liberdade são as maneiras de reduzir o indivíduo a condição análoga à de escravo, devidamente previstas no estatuto penal. ${ }^{7}$

Destaque-se que antes da alteração, o Código Penal apenas previa tal proibição de forma genérica: "Art. 149. Reduzir alguém à condição análoga a de escravo: Pena - reclusão, de 2 (dois) a 8 (oito) anos. "

A partir da apresentação das formas escravocratas, verifica-se o acréscimo de mais objeto jurídico a referida tipificação do crime de escravidão moderna, passando a incorporar além da restrição da liberdade de locomoção, a dignidade da pessoa humana.

Tem-se que o Código Penal prevê de forma autoexplicativa as condutas tipificadoras do delito, acrescentando duas hipóteses que necessita da subjetividade

\footnotetext{
${ }^{7}$ Art. 149. Reduzir alguém a condição análoga à de escravo, quer submetendo-o a trabalhos forçados ou a jornada exaustiva, quer sujeitando-o a condições degradantes de trabalho, quer restringindo, por qualquer meio, sua locomoção em razão de dívida contraída com o empregador ou preposto: Pena reclusão, de dois a oito anos, e multa, além da pena correspondente à violência. $\S 1^{\circ}$ Nas mesmas penas incorre quem: I - cerceia o uso de qualquer meio de transporte por parte do trabalhador, com 0 fim de retê-lo no local de trabalho; II - mantém vigilância ostensiva no local de trabalho ou se apodera de documentos ou de objetos pessoais do trabalhador, com o fim de retê-lo no local do trabalho. $\S 2^{\circ}$ A pena é aumentada de metade, se o crime é cometido:I - contra criança e adolescente;II - por motivo de preconceito de raça, cor, etnia, religião ou origem.
} 


\section{Personalidade Acadêmica Homenageada:}

Carlos Aurélio Mota de Souza (Universidade Ibirapuera - UNIB)

do julgador para a constatação, quais sejam: jornadas excessivas e condições degradantes de trabalho. Tais condutas demandam uma interpretação mais acurada, acarretando divergências e dificuldades para os órgãos responsáveis pelo enfrentamento do trabalho escravo. (BRITTO FILHO, 2016).

Desta forma, é importante destacar que na análise dessas modalidades deverá ser levado em consideração que meras irregularidades trabalhistas não serão consideradas para a configuração do delito. Torna-se necessária a demonstração da prova inequívoca da jornada excessiva e das condições desumanas de trabalho.

Rogério Greco posiciona-se no que concerne à jornada excessiva como sendo as horas laboradas suficientes para aniquilar completamente as forças do trabalhador, afetando sobremaneira sua saúde física e mental, o que difere da simples ausência do controle de horas. A presunção jamais poderá ser utilizada nessa análise. (GRECO, 2010).

Britto Filho salienta que o cerceamento da liberdade não constitui fator determinante para à configuração do delito, sendo imprescindível a existência da relação de dominação do autor sobre a vítima. Outro fato importante a ser considerado é que esse domínio seja capaz de anular a vontade da pessoa escravizada. (BRITTO FILHO, 2016).

A utilização do trabalho escravo é uma realidade na sociedade, embora não seja tão visível e na maioria das vezes as vítimas escravizadas não se enxergam com tal. Resta manifesto que os fatores sociais e econômicos são responsáveis pela evidenciação de formas modernas de escravidão, como migração de pessoas e a má distribuição de renda, o que ocasiona a miséria estabelecida na sociedade fruto de uma desigualdade socioeconômica expressiva.

Essa realidade engloba uma série de questões sociais que representam a situação de vulnerabilidade das vítimas por se encontrarem fragilizadas devido à sua condição social, o que corrobora para o fato de se tornar alvo fácil para os autores deste tipo de delito. 


\section{Personalidade Acadêmica Homenageada:}

\section{Carlos Aurélio Mota de Souza (Universidade Ibirapuera - UNIB)}

\section{A CRISE DOS DIREITOS HUMANOS DECORRENTE DA SUA INEFETIVIDADE}

A Constituição Federal estabelece que a igualdade, a liberdade, a livre iniciativa e a dignidade humana constituem fundamentos da República. Entretanto, esses direitos fundamentais estão muito distantes da sua efetivação, devido ao contexto econômico atual que corrobora com a instalação da desigualdade nas relações de trabalho, beneficiando sempre aqueles que detêm o poder econômico, submetendo as pessoas mais necessitadas às condições por eles estabelecidas. É, justamente, essa a situação que se atribui à chamada escravidão contemporânea.

Os seres humanos encontram-se, hoje, num mundo em que suas ações estão cada vez mais reguladas e pautadas pelo viés econômico, contribuindo para um distanciamento da humanidade, ocasionada pela necessidade incessante da obtenção de vantagens econômicas. Essa busca desenfreada pelo poder acarreta a perenidade de condutas consagradoras da violência através do individualismo e do desrespeito à dignidade humana.

Ademais, o capitalismo constitui um sistema que estabelece para a sociedade um modo de produção exacerbado. Produz-se além do necessário, respaldando-se exclusivamente na necessidade do consumo, estimulado pelo próprio sistema. Essa prática favorece a perpetuação de condutas de empregadores em total desacordo com o direito fundamental ao trabalho digno, com a legislação trabalhista e com a qualidade de vida almejada pelos trabalhadores vítimas da escravidão moderna. (SAFIOTI, 2013).

$\mathrm{Na}$ era globalizada da sociedade atual, condutas humanas encontram-se cada vez mais subjugadas à ideologia neoliberal e totalmente alheias ao impacto das novas tecnologias sobre a natureza e o ser humano, o que ocasiona situações em que inúmeras pessoas não têm condições mínimas de sobrevivência. Vivenciam-se desigualdades sociais, discriminações, bem como, o empobrecimento das pessoas, refletindo negativamente na ação humana representada pelo trabalho. (RUBIO, 2004, pág. 139-140). É justamente a ilusão de uma vida melhor que transmuta a sua condição de pessoa humana, passando a ser considerada mera mercadoria.

Constata-se que o homem está inserido numa modernidade, onde as relações 


\title{
Personalidade Acadêmica Homenageada:
}

Carlos Aurélio Mota de Souza (Universidade Ibirapuera - UNIB)

humanas encontram-se fragilizadas, tendo como pressuposto a transformação dos seres humanos em mercadorias, o que contribui para a objetificação do indivíduo e violação dos direitos fundamentais que Ihes são inerentes. Vivencia-se uma modernidade líquida, a qual constitui nossa época atual, em que as relações de trabalho se desgastam progressivamente, ocasionando o desrespeito as suas regulamentações. (BAUMAN, 2014).

Desta forma, os indivíduos habitam um mundo onde predominam a objetificação e descartabilidade das pessoas. Verifica-se que a exploração do homem visa à obtenção apenas do lucro, o que afeta negativamente os direitos fundamentais dos indivíduos (BAUMAN, 2014).

Por conseguinte, verifica-se que o descrito acima representa a crise atual dos direitos humanos. Justamente esses direitos que foram tão enaltecidos e desenvolvidos no pós-guerra a partir de 1945, com a Declaração Universal dos Direitos Humanos, a qual reconheceu direitos próprios dos seres humanos que não poderiam ser violados pelo Estado (Ávila, 2014), estão sendo mais uma vez desprezados em meio ao desrespeito à dignidade da pessoa humana, ao trabalho digno, às jornadas de trabalho, ao repouso intrajornadas, além da exclusão vivenciada pelas classes economicamente desfavorecidas, sendo fator determinante para o estabelecimento da vulnerabilidade do trabalhador vítima do trabalho escravo.

Piovesan e Kamimura (2013) se posicionam neste sentido ao discorrer:

\begin{abstract}
A ética dos direitos humanos é a ética que vê no outro um ser merecedor de igual consideração e profundo respeito, dotado do direito de desenvolver suas potencialidades humanas, de forma livre, autônoma e plena. É a ética orientada pela afirmação da dignidade e pela prevenção ao sofrimento humano. (PIOVESAN e KAMIMURA, p. 108, 2013).
\end{abstract}

As condutas perpetradas em relação às vítimas desse fenômeno retratam exatamente o oposto do defendido, pois vivenciam a violência física nas formas de maus-tratos, condições de subsistência precárias, morte, lesões corporais. Acrescente-se a violência psicológica enfrentada por essas vítimas quando são constantemente ameaçadas e confinadas, o que muitas vezes as levam a cometer o 


\section{Personalidade Acadêmica Homenageada:}

Carlos Aurélio Mota de Souza (Universidade Ibirapuera - UNIB)

suicídio. Além, evidentemente, da violação da sua vida social, quando são obrigadas romperem os vínculos familiares.

$\mathrm{Na}$ visão das autoras suso mencionadas, deverá existir uma integração normativa dos padrões normativos dos organismos internacionais com as medidas administrativas, judiciais e legislativas visando a efetividade do cumprimento do compromisso assumido pelo Brasil. Ademais, ressalte-se que o combate a esta prática negativa será alcançado com a promoção da efetividade dos direitos humanos, através do direito ao trabalho decente, do direito a um padrão de vida adequado, da liberdade de locomoção e da proibição de discriminação." (PIOVESAN e KAMIMURA, p.120, 2013).

Torna-se imperioso trazer o posicionamento de Morais (2011) em relação a concretização dos direitos humanos, como medida de solucionar a crise atual dos direitos humanos:

[...] (Os direitos humanos) surgem sempre como condição fundante da vida, impondo aos agentes público-jurídico-sociais a tarefa de agirem no sentido de permitir que a todos seja consignada a possibilidade de usufruí-los em benefício próprio e comum ao mesmo tempo. Assim como os direitos humanos se dirige a todos, o compromisso com sua concretização caracteriza tarefa de todos, em um comprometimento comum com a dignidade comum [...]. (MORAIS, 2011, p. 88).

Conforme exposto no texto transcrito, é dever de todos, inclusive do Estado, buscar a efetivação dos direitos humanos. A Constituição Federal de 1988 traz em seu art. 3ำ, como objetivo da República do Brasil, a construção de uma sociedade livre, justa e solidária. Tais objetivos se configuram verdadeiros valores na Ordem Jurídica interna que devem ser buscados através da aplicação da ordem econômica disposta na Constituição.

O sistema constitucional decorre de profundas mudanças na ordem jurídica surgidas a partir do início do século XX, onde a economia livre de mercado, fundada no liberalismo que ganhou força a partir dos ideários da Revolução Francesa, já não mais correspondia aos anseios de igualdade, liberdade e justiça traçados como fundamentos daquela ordem jurídica. Tudo isso corroborado pelo desenvolvimento tecnológico e econômico que, influenciados pela Revolução Industrial, o movimento 


\section{Personalidade Acadêmica Homenageada:}

Carlos Aurélio Mota de Souza (Universidade Ibirapuera - UNIB)

fabril ganhou força, havendo aumento do número de trabalhadores migrando do campo para as cidades e, por consequência, submetendo-se ao poder do capital, que impunha as condições de trabalho degradantes, desumanas, à margem de quaisquer direitos que garantissem um trabalho salubre, digno e justo.

A insatisfação contra os desequilíbrios causados com o crescimento irreversível do modelo de capital como força primeira do desenvolvimento econômico do modelo liberal, uma vez desfeito o modo feudal de produção, fez com que o Estado repensasse o seu modo de agir na ordem jurídica vigente. É nessa época que, premido pela necessidade de reequilibrar a ordem econômica e reafirmar a igualdade, justiça e equilíbrio econômico trazidos como fundamento do Estado constitucional então vigente, que o Estado passa a intervir na Ordem social e econômica por meio da Ordem Jurídica Constitucional, cujos marcos legais dessa mudança se deram com a Constituição Mexicana de 1917 e a Constituição de Weimar, na Alemanha, em 1919.

No Brasil, a Constituição de 1937 já previa a intervenção do Estado na ordem econômica como mecanismo de alcance dos direitos fundamentais e sociais, incorporando à ordem Jurídica, a ordem econômica e social. Essa fase do Estado dualista é marcada pela busca do desenvolvimento econômico aliado ao bem-estar social. Nesse sentido que a Constituição Federal de 1988, ao trazer seus objetivos fundamentais, incorpora na Ordem Jurídica econômica e social a necessidade de o Estado intervir e buscar o alcance dos valores trazidos pela Constituição.

Importante, assim, notar, que a normatização de políticas públicas estatais se faz por força dessa compreensão dos valores constitucionais, traduzidos por princípios e regras que se correlacionam para alcançar os fundamentos da República do Brasil.

Portanto, a observância, pelo Estado, desses valores, é de primordial importância para que a liberdade seja alcançada em todos os seus aspectos, seja pela livre iniciativa, pela liberdade econômica, pela isonomia, pelo respeito ao trabalho digno, sem, contudo, deixar de lado os objetivos voltados ao crescimento econômico e bem-estar social.

Constata-se, então, que respeitar de forma concatenada os valores traçados pela coordenação de princípios trazidos pela atual Ordem Constitucional é respeitar o 


\section{Personalidade Acadêmica Homenageada:}

\section{Carlos Aurélio Mota de Souza (Universidade Ibirapuera - UNIB)}

alcance à dignidade da pessoa humana, que se traduz nos valores acima mencionados e que, sem o importante papel do Estado pelo seu poder normativo e interventor, não há como reduzir o desequilíbrio econômico-social que tem se traduzido na escravidão contemporânea, cujo reflexo se dá justamente na supressão desses direitos fundamentais do cidadão.

\section{CONCLUSÃO}

O trabalho escravo contemporâneo é constatado sempre que o trabalhador for exposto a condições degradantes de trabalho e de vida, com a impossibilidade de desvinculação desta realidade.

O aumento do trabalho informal, caracterizado pelas condições laborativas precárias é responsável por diversas irregularidades na relação de trabalho, o que contribui para a aniquilação do rol de direitos elencados na Constituição Federal, na Consolidação das Leis do Trabalho e em diversos dispositivos internacionais ratificados pelo Brasil, com é o caso da Declaração Universal de Direitos Humanos.

Diante dessa situação, as vítimas escravizadas entram na engrenagem desse sistema apenas com o objetivo de sobrevivência, acreditando ser a única oportunidade que possui. Na realidade, são impelidas a se submeterem a condições desumanas, colocando sua vida em risco, quando são reduzidas à condição análoga a de escravo.

Existe um conjunto de fatores sociais cuja marca central é a pobreza, que é responsável pela submissão desses trabalhadores aos detentores do poder econômico, o que faz com que as vítimas escravizadas não se reconheçam como tal.

Nesse contexto, é de fundamental importância empreender um olhar para as vítimas escravizadas no sentido de reconhecê-las como sujeito de direitos, dentro de sua peculiaridade e sua particularidade.

Ressalte-se que este problema deverá ser enfrentado não apenas com a penalização do empregador escravocrata, porque não resolve de imediato a vulnerabilidade da vítima escravizada, mas deve ser enfrentado sob o viés da 


\section{Personalidade Acadêmica Homenageada:}

Carlos Aurélio Mota de Souza (Universidade Ibirapuera - UNIB)

promoção da qualificação e da informação necessárias às vítimas que se encontram nesta situação. $O$ fato de não possuírem conhecimento é condicionante para a submissão à condição laborativa em análise.

É imprescindível o enfrentamento da vulnerabilidade das vítimas das práticas escravocratas porque estão inseridas num processo cultural oriundo dos processos social e econômico e que muitas vezes nem se reconhecem como escravos, posto que vivenciam a falta de oportunidades concretas, responsáveis pelo tolhimento da capacidade reescrever suas histórias da forma que almejam.

A partir de então, deverá haver melhoria no sistema de fiscalização e atuação do Ministério Público do Trabalho e Ministério Público Federal que encontram dificuldades na ausência de uma estrutura que amplie a investigação. Além disso, é imprescindível o despertar da sociedade para esta realidade, porque esse segmento é peça essencial para o enfrentamento deste fenômeno degradante.

O estabelecimento de políticas pública concretas com a disponibilização de cursos alfabetizantes e profissionalizantes, para que essas vítimas consigam se libertar do ciclo vicioso da escravidão moderna. Isso só será viável com a conscientização social para a existência da escravidão e com a eliminação da situação de vulnerabilidade dessas pessoas.

Desta forma, verifica-se a necessidade de trazer esse tema para discussão acadêmica, no sentido de que sejam conduzidos estudos profundos e pesquisas a respeito desta temática, além de proporcionar a apresentação de planos de ações para a concretização de políticas públicas efetivas para a prevenção e combate deste fenômeno econômico-social tão desumano.

\section{REFERÊNCIAS}

ARENDT, Hannah. Origem do Totalitarismo. Tradução Roberto Raposo. São Paulo: Companhia das Letras, 2012.

ÁVILA, Flávia de. Direito e Direitos Humanos: Abordagem Histórico-Filosófica e Conceitual. $1^{\underline{a}}$ edição. Curitiba: Appris, 2014. 
Personalidade Acadêmica Homenageada:

Carlos Aurélio Mota de Souza (Universidade Ibirapuera - UNIB)

BAUMAN, Zygmunt. Cegueira Moral: A perda da sensibilidade na modernidade líquida. Rio de Janeiro: Zahar, 2014.

BRASIL. Constituição (1988). Constituição da República Federativa do Brasil. Brasília, DF: Senado, 1988.

BRASIL. Decreto-lei $n^{\circ}$ 2.848, de 7 de dezembro de 1940. Institui o Código Penal Brasileiro. Disponível em: < http://www.planalto.gov.br/ccivil_03/decretolei/Del2848compilado.htm>. Acesso em: 30 de março de 2017.

BRITO FILHO, José Cláudio Monteiro de. Trabalho com redução do homem a condição análoga à de escravo e a dignidade da pessoa humana. Disponível em: http://www.pgt.mpt.gov.br/publicações. Acesso em 08/05/2017.

BRITO FILHO, José Cláudio Monteiro de. Trabalho Decente: Análise Jurídica da Exploração do Trabalho - Trabalho Escravo e outras formas de Trabalho Indigno. 4.ed. São Paulo: LTR, 2016.

GÓMEZ, Rina Cáceres. El trabajo esclavo em Costa Rica. Revista de História, [S.I.], n. 39, july 2001. ISSN 2215-4744. Disponível em: <http://www.revistas.una.ac.cr/index.php/historia/article/view/2023> . Acesso em: 28 de julho de 2017.

ORGANIZAÇÕES DAS NAÇÕES UNIDAS. ONU. Recomendação sobre trabalho forçado (medidas complementares) n. 203/2014. Disponível em: http://www.ilo.org/dyn/normlex/es/f?p=NORMLEXPUB: 12100:0::NO::P12100_INSTRUMENT_ID:3174688. Acesso em: 29 de maio de 2018.

Declaração Universal dos Direitos Humanos. Resolução no 217 A (III) da Assembleia Geral das Nações Unidas. Dez. 1948. Disponível em: $<$ <ttp://www.direitoshumanos.usp.br/index.php/Declaração-Universal-dos-DireitosHumanos/declaracao-universal-dos-direitos-humanos.html $>$. Acesso em, 30 de maio de 2016.

ORGANIZAÇÃO DOS ESTADOS AMERICANOS. OEA. Convenção Interamericana sobre Direitos Humanos. Disponível em:< https://www.cidh.oas.org/basicos/portugues/c.convencao_americana.htm>. Acesso em: 24 de maio de 2017.

ORGANIZAÇÃO INTERNACIONAL DO TRABALHO. OIT. Convenção 29 Convenção concernente à Trabalho Forçado ou Obrigatório, adotada pela Conferência em sua Décima Quarta Sessão - Genebra, 28 de junho de 1930 (com as modificações da Convenção de Revisão dos artigos finais, de 1946). Disponível em: <http://www.planalto.gov.br/ccivil_03/decreto/antigos/d41721.htm>. Acesso em 20 de abril de 2017. 
Personalidade Acadêmica Homenageada:

Carlos Aurélio Mota de Souza (Universidade Ibirapuera - UNIB)

Convenção 105 - Convenção concernente à abolição do trabalho forçado, promulgado pelo Decreto $\mathrm{n}^{\circ} \mathbf{5 8 . 8 2 2}$, de 14 de julho de 1966. Disponível em: <http://www.planalto.gov.br/ccivil_03/decreto/1950-1969/D58822.htm>. Acesso em 20 de abril de 2017.

ILO. Protocolo de 2014 relativo à convenção do trabalho Forçado de 1930. Disponível em: http://www.ilo.org/dyn/normlex/es/f?p=NORMLEXPUB: 12100:0::NO::P12100_ILO_CODE:P029. Acesso em 20 de maio de 2018.

GRECO, Rogério. Curso de Direito Penal: parte especial, vol. II: introdução à teoria geral da parte especial: crimes contra a pessoa. $7^{\mathrm{a}}$ ed. Niterói: Ímpetos, 2010.

GUERRA, Sidney. Direitos Humanos: curso complementar. São Paulo: Saraiva, 2013.

MORAIS, José Luiz Bolzan de. As Crises do Estado e da Constituição e a Transformação Espaço-Temporal dos Direitos Humanos. $2^{\mathrm{a}}$ ed. rev. ampl. Porto Alegre: Livraria do Advogado Editora, 2011.

ORGANIZAÇÃO DAS NAÇÕES UNIDAS. ONU. Declaração Universal dos Direitos Humanos. Resolução № 217 A (III) da Assembleia Geral das Nações Unidas. Dez. 1948. Disponível em: <http://www.direitoshumanos.usp.br/index.php/DeclaraçãoUniversal-dos-Direitos-Humanos/declaracao-universal-dos-direitos-humanos.html>. Acesso em, 30 de maio de 2016.

PAGLIARINI, Alexandre Coutinho. Teoria geral e crítica do direito constitucional e internacional dos direitos humanos. In: PAGLIARINI, Alexandre Coutinho; DIMOULIS, Dimitri (coord.). Direito constitucional e internacional dos direitos humanos. Belo Horizonte: Fórum, 2012.

PIOVESAN, Flávia. Direitos Humanos e Justiça Internacional. 6aㅗ edição. São Paulo: Saraiva, 2015a.

PIOVESAN, Flávia. Temas de Direitos Humanos. 8ª ed. São Paulo: Saraiva, 2015b.

PIOVESAN, Flávia; KAMIMURA, Akemi. Tráfico de pessoas sob a perspectiva de direitos humanos: prevenção, combate, proteção e cooperação. In: Tráfico de pessoas uma abordagem para os direitos humanos/Secretaria Nacional de Justiça. ANJOS, Fernanda Alves dos... [et al.]. 1 ed. Brasília: Ministério da Justica, p. 105-131, 2013.

RAMOS, André de Carvalho. Curso de Direitos Humanos. $3^{a}$ ed. rev., atual, e ampl. São Paulo: Saraiva, 2016.

RAMOS, André de Carvalho. Teoria Geral dos Direitos Humanos na Ordem Internacional. 5aㅡ ed. São Paulo: Saraiva, 2015. 
Personalidade Acadêmica Homenageada:

Carlos Aurélio Mota de Souza (Universidade Ibirapuera - UNIB)

ROGRÍGUEZ, Vanesa. Prohibición de esclavitud y servidumbre. In: Convención Americana de Derechos Humanos y su proyeción en el Derecho Argentino. 1 ed. Buenos Aires: La Ley/Departamento de Publicaciones de la Facultad de Derecho, 2013.

RUBIO, David Sánchez. "Direitos Humanos, Ética da vida Humana e Trabalho Vivo". In: WOLKMER, Antônio Carlos (org.). Direitos Humanos e filosofia jurídica na América Latina. Rio de Janeiro, Lumens Juris, 2004.

SAFFIOTI, Heleieth I. B. A mulher na sociedade de classes. $3^{\text {a }}$ edição. São Paulo: Expressão Popular, 2013.

SARLET, Ingo Wolfgang. A eficácia dos direitos fundamentais: uma teoria geral dos direitos fundamentais na perspectiva constitucional. 12 ${ }^{\mathrm{a}}$ edição. Porto Alegre: Livraria do Advogado Editora, 2015.

TREVISAN, Elisaide. Trabalho Escravo no Brasil Contemporâneo: entre as presas da clandestinidade e as garras da exclusão. Curitiba: Juruá, 2015. 